\title{
AN INTEGRATED MODELING APPROACH FOR SIMULATING OIL SPILL AT THE STRAIT OF BOHAI SEA
}

\author{
Jinhua Wang ${ }^{1}$ and Jinshan Zhang ${ }^{1}$
}

\begin{abstract}
A three-dimensional integrated model is developed for simulating oil spills transport and fate in seas. The model contains two main modules, flow and transport-fate module. The transport module uses an unstructured finite volume wave-current coupling model, giving a more accurate result compared to structured model, especially for a region has a complex coastline. In the transport-fate module the oil dispersion is solved using a particle-tracking method. Horizontal diffusion is simulated using a random walk techniques in a Monte Carlo framework while vertical diffusion process is solved based on the Langeven equation. The model simulates the most significant processes which affect the motion of oil particles, such as: advection, surface spreading, evaporation, dissolution, emulsification, and turbulent diffusion, the interaction of the oil particles with the shoreline, sedimentation and the temporal variations of oil viscosity, density, and surface-tension. This model has been applied to simulate the oil spill accident at the strait of Bohai Sea. In comparison with the observations, the numerical results indicate that the model is reasonably accurate.
\end{abstract}

Keywords: Oil-spill modeling; finite-volume method; oil particles; 3-D; unstructured grid

\section{INTRODUCTION}

Oil spills in the sea have become common because of growing development of the oil industry, especially seagoing oil transportation. When liquid oil is spilled on the surface of the sea it spreads, forming a thin film, the so-called oil slick. Under surface-wave action and upper layer turbulence, a coherent oil slick will break up into small particles. The oil particles move horizontally on the surface owing to current, wind-induced surface speed, wave drift and horizontal diffusion. Because of seasurface agitation, some particles entrain and diffuse in the water column. Once in the water column, the displacements of entrained droplets are considered in the three spatial directions. Vertical displacements are due to buoyancy and turbulent diffusion. Figure 1 is a schematic diagram showing these processes.

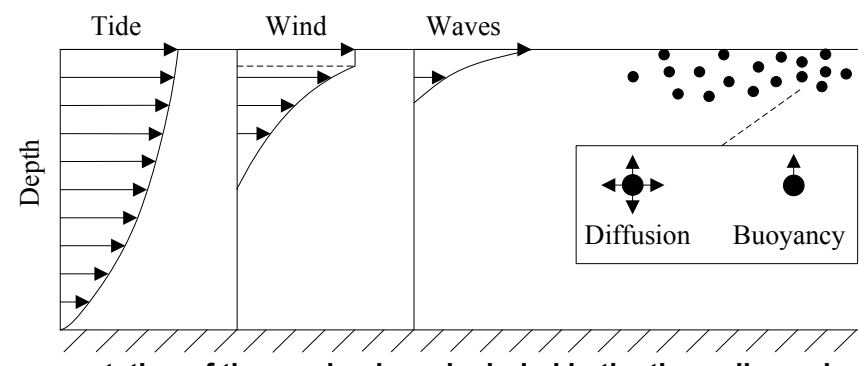

Figure 1. Schematic representation of the mechanisms included in the three-dimensional model.

During the last three decades, many investigators have studied the transport and final fate of oil spills based on the trajectory method (Chao et al., 2001; Chao et al., 2003; Lonin, 1999; Periáñez, 2007; Periáñez and Pascual-Granged, 2008; Shen and Yapa, 1988; Shen et al., 1986; Wang et al., 2005; Wang et al., 2008; Yapa et al., 1994). Among these oil-spill models, many focus on the surface movement of oil spills. There has been little attention given to the hydrodynamic model. Moreover, the hydrodynamic parameters of most spill models are provided by the structured finite difference ocean model. This method is acceptable when the geometry is regular or smooth. When facing an irregular geometry, however, such as the Bohai Strait, with numerous barrier islands and tidal creek complexes, the unstructured grid seems better than the structured grid for capturing suitable physics and reaching a certain accuracy of numerical simulation (Chen et al., 2007). On the other hand, waves at sea play animportant role in the transport and fate of oil particles. Wave motion influences oil behavior in many ways. Wave drift, a netforward movement of waves owing to the not-closed orbitals, transports the oil on the surface, whereas breaking waves disperse and mix the oil with the water. Because of the waves, emulsification of the oil in the water can occur. The oil thickness also depends on the local wave climate. The accurate simulation of the surface wave is therefore important for the oil-spill simulation.

\footnotetext{
${ }^{1}$ State Key Laboratory of Hydrology-Water Resources and Hydraulic Engineering, Nanjing Hydraulic Research Institute, Nanjing 210029, PR China
} 
Considering the importance of these processes it is necessary to develop a robust oil-spill-simulation system that can provide accurate hydrodynamic parameters, such as waves, ocean currents and turbulence even in an area of complex geometries.

In this paper, a three-dimensional oil-spill transport and fate model, based on the Lagrangian discrete particle algorithm, is developed to simulate the processes of advection, spreading, turbulent diffusion, evaporation, emulsification and dissolution. Horizontal-plane dispersion is calculated on the basis of the random walk technique, whereas vertical particle movements are taken into account on the basis of the Langeven equation and buoyancy effect in the following model. To represent the structure of coastal currents more accurately, a three-dimensional (3-D) unstructured finite-volume ocean-wave coupled model is developed. This is the first time, to our knowledge, that a 3-D, unstructured-grid, primitive-equation, finite-volume ocean-wave model is coupled to provide hydrodynamic parameters required by a transport-fate module. An application of the developed model to simulate the oil-spill accident in the Bohai Sea is also presented.

\section{MATHEMATICAL MODEL}

The model consists of two main modules: flow module and transport-fate module. The overall structure of the model is shown in Figure 2. The reader is referred to Wang and Shen. (2010) for details about the flow module and the transport-fate module.

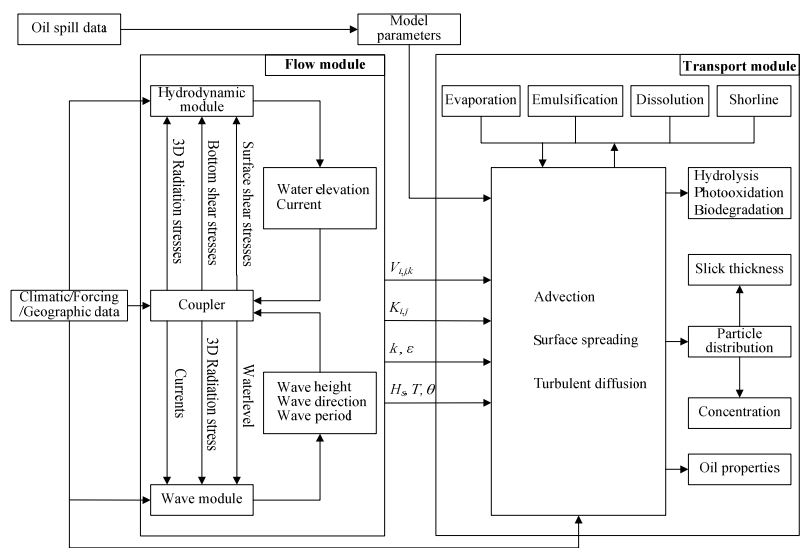

Figure 2. Flow diagram of the computation process in the integrate model system.

\section{APPLICATION OF THE MODEL TO THE OIL SPILL ACCIDENT IN THE BOHAI STRAIT}

A three-dimensional integrated oil spills model is developed based on the above analytical formulation and used to simulate the oil spill accident which occurred in the Bohai Strait. The simulated results of the oil slicks after the spillage are presented and discussed.

On 8 June 1990, two ships collided in the Bohai Strait $\left(38^{\circ} 32^{\prime} 48^{\prime \prime} \mathrm{N}, 120^{\circ} 56^{\prime} 42^{\prime \prime} \mathrm{E}\right)$ at 2:00 a.m. (Beijing time) with one seriously damaged and its tank broken. On 14 June, the amount of heavy fuel released continuously from the broken tank was estimated to be of the order of 250 350 tons. At the same time, aerial surveys were carried out by a team of Chinese experts and the distribution of the spilled oil on the sea surface issued (Zhang et al., 1991). Some environmental factors observed by a monitoring vessel in the accident site indicated that the speed of wind, blowing from the south, did not exceed $4 \mathrm{~m} / \mathrm{s}$ during those days. After 15 June, the oil spill continued but the survey had to be cancelled due to very bad weather conditions. 


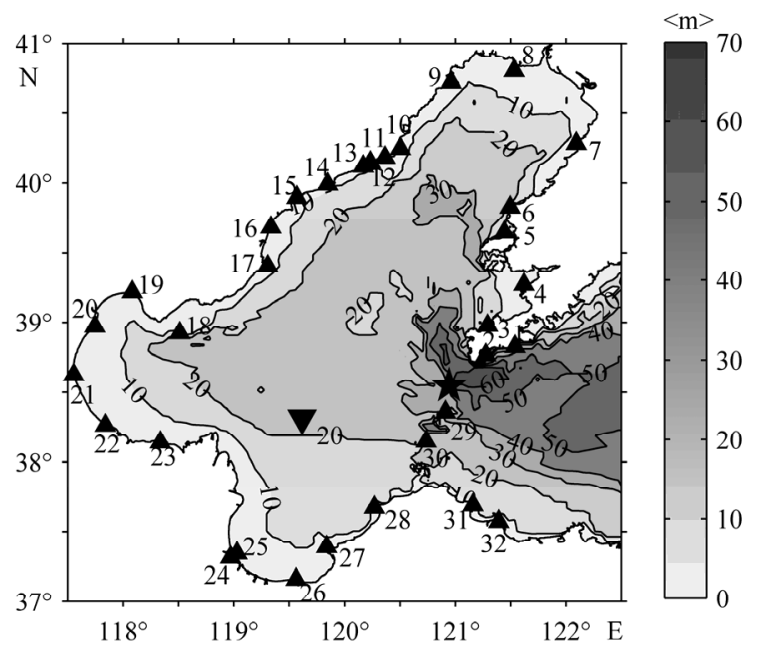

Figure 3. (a) Model domain and bathymetry of the Bohai Sea. Numbers next to $\Delta$ denote the tidal stations where tidal harmonic constants are compared between simulations and observations (see Figure 6). $\nabla$ denotes the tidal current observation station and $\star$ denotes the oil spill location.
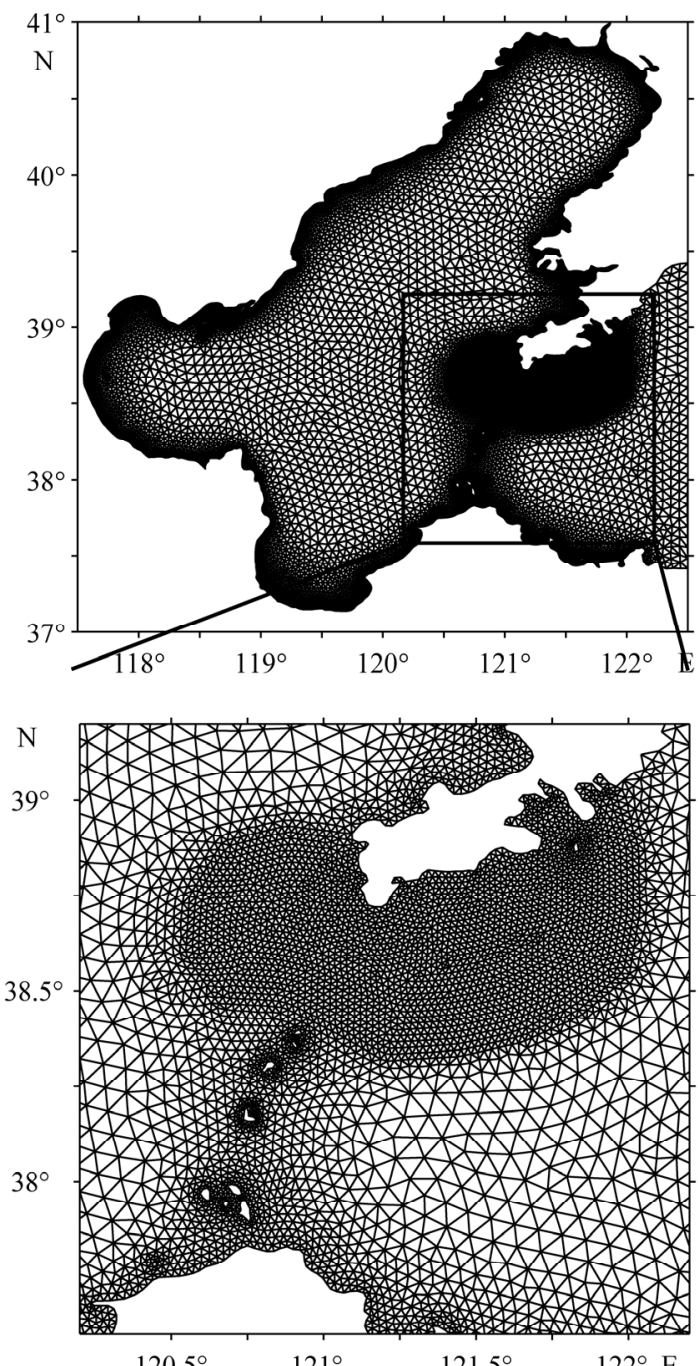

Figure 4. Unstructured grid of the flow module. The downward panel provides an enlarged view of the grid around the oil spill location. 


\begin{tabular}{|c|c|c|c|c|}
\hline Simulation time & $\begin{array}{l}\text { Spill time step, } \\
\qquad \Delta t\end{array}$ & oil particle number, $N_{0}$ & $\begin{array}{c}\text { Sea bed } \\
\text { deposition } \\
\text { coefficient }\end{array}$ & $\begin{array}{l}\text { Emulsification } \\
\text { coefficient }\end{array}$ \\
\hline \multirow{2}{*}{$\begin{array}{c}8 \text { days } \\
\text { Resurfacing } \\
\text { coefficient }\end{array}$} & $12 \min$ & 5760 & $10^{-5} \mathrm{~s}^{-1}$ & $10^{-6} \mathrm{~s}^{-1}$ \\
\hline & Buoyant velocity & Air temperature & Water viscosity, & Total spilled volume \\
\hline 1.0 & $0.00254 \mathrm{~m} / \mathrm{s}$ & $10.0^{\circ} \mathrm{C}$ & $1.311 \times 10^{-6} \mathrm{~m}^{2} / \mathrm{s}$ & $300.0 \mathrm{~m}^{3}$ \\
\hline Oil type & $\begin{array}{l}\text { Ice cover } \\
\text { condition }\end{array}$ & Wind velocity & Spill location & Spill condition \\
\hline $\begin{array}{l}\text { Heavy fuel (sp. } \\
\text { gr. }=0.965)\end{array}$ & Open water & $\begin{array}{c}0 \sim 192 \mathrm{hrs}, 3.0 \mathrm{~m} / \mathrm{s} \text { from } \\
\text { SSW }\end{array}$ & $\begin{array}{l}\left(38^{\circ} 32^{\prime} 48^{\prime \prime} \mathrm{N}\right. \\
\left.120^{\circ} 56^{\prime} 42^{\prime \prime} \mathrm{E}\right)\end{array}$ & $\begin{array}{l}\text { Continuous spill, } \\
\text { duration }=6 \text { days }\end{array}$ \\
\hline Oil viscosity & Surface tension & $\begin{array}{c}\text { Evaporation } \\
\text { parameters } C\end{array}$ & $\begin{array}{c}\text { Solubility } \\
\text { parameter, } \alpha\end{array}$ & $\begin{array}{c}\text { Solubility } \\
\text { parameter, } K S_{0}\end{array}$ \\
\hline $8.6 \times 10^{-4} \mathrm{~m}^{2} / \mathrm{s}$ & $0.02 \mathrm{~N} / \mathrm{m}$ & 7.88 & 0.423 day $^{-1}$ & $0.0184 \mathrm{~g}^{-2} \mathrm{~h}^{-1}$ \\
\hline
\end{tabular}

A high-resolution circulation model is required to describe the complex hydrodynamics of coastal areas of the Bohai Sea. The computational domain of this model, within $37^{\circ} 07^{\prime} \mathrm{N}-41^{\circ} \mathrm{N}$ latitude and $117^{\circ} 35^{\prime} \mathrm{E}-122.5^{\circ} \mathrm{E}$ longitude, is shown in Figure 3. In order to fit the irregular coastline better, the horizontal resolution should be about $1.5 \mathrm{~km}$ around the coast and about $7 \mathrm{~km}$ in the interior and near the open boundary; a refined grid is used around the oil spill location at the Bohai Strait. The computational grid is shown in Figure 4. In the vertical dimension the grid comprises 15 uniformly distributed $\sigma$ layers. The model is driven by tidal forcing at the open boundary. The harmonic constants of $M_{2}, N_{2}, S_{2}, K_{2}, K_{1}, O_{1}$ and $P_{1}$ obtained from the coastal gauges at the northern and southern coasts were interpolated onto the open boundary. The climatological temperature and salinity derived from the Marine Atlas of the Bohai Sea, Yellow Sea and East China Sea (Editorial Board for Marine Atlas, 1992) (hereafter referred to as 'the atlas') are used as our model initial conditions. At the sea surface, the model is forced by monthly climatological SST and SSS, respectively. The monthly climatological wind field derived from the QuickSCAT sea surface vector winds is used to drive the model. The external and internal mode time steps were 10.0 and $180.0 \mathrm{~s}$. The model is spun up as 1 January 1989 until the time of the oil-spill accident, then the wind speed is changed to $3 \mathrm{~m} / \mathrm{s}$ in an SSW direction, and another 8 days are simulated to provide the hydrodynamic parameters to the transportfate module.

Since the transport-fate module was designed in a z-level coordinate system, the simulated velocity and diffusivity data from flow module were converted from sigma levels to z-levels, and linear interpolation between the two types of levels was implemented. The transport module had 140 vertical levels; the vertical resolution was $0.5 \mathrm{~m}$. In the horizontal, the two modules share the same resolution.

The simulation time of the transport-fate module is 8 days, starting from 8 June 1990 at 2:00 when the accident happened. During this time 5760 oil particles were released. It is assumed from the observations that a continuous release of six days is reasonable. The time interval between two releases was set as 1 hour, with 40 oil particles released each time. The input data are summarized in Table 1.

\section{RESULTS AND DISCUSSION}

Model-predicted amplitudes and phases of tidal elevation and tidal current were output at each vertex of a triangle and calibrated using the existing tidal observational data. Computed tidal charts for the and tides are presented in Figure 5. The cotidal chart lines are in good agreement with the atlas. A comparison of tidal harmonic constants at 32 stations between model results and observations indicates a good reproduction of the four major tidal constituents in the Bohai Sea (Figure 6). The tidal ellipse charts show that the tidal current reaches its maximum speed at about $38^{\circ} 50^{\prime} \mathrm{N}, 121^{\circ} \mathrm{E}$. This location roughly coincides with the place of the accident, indicating that tidal current may exert a significant effect on spreading the spilled oil. 

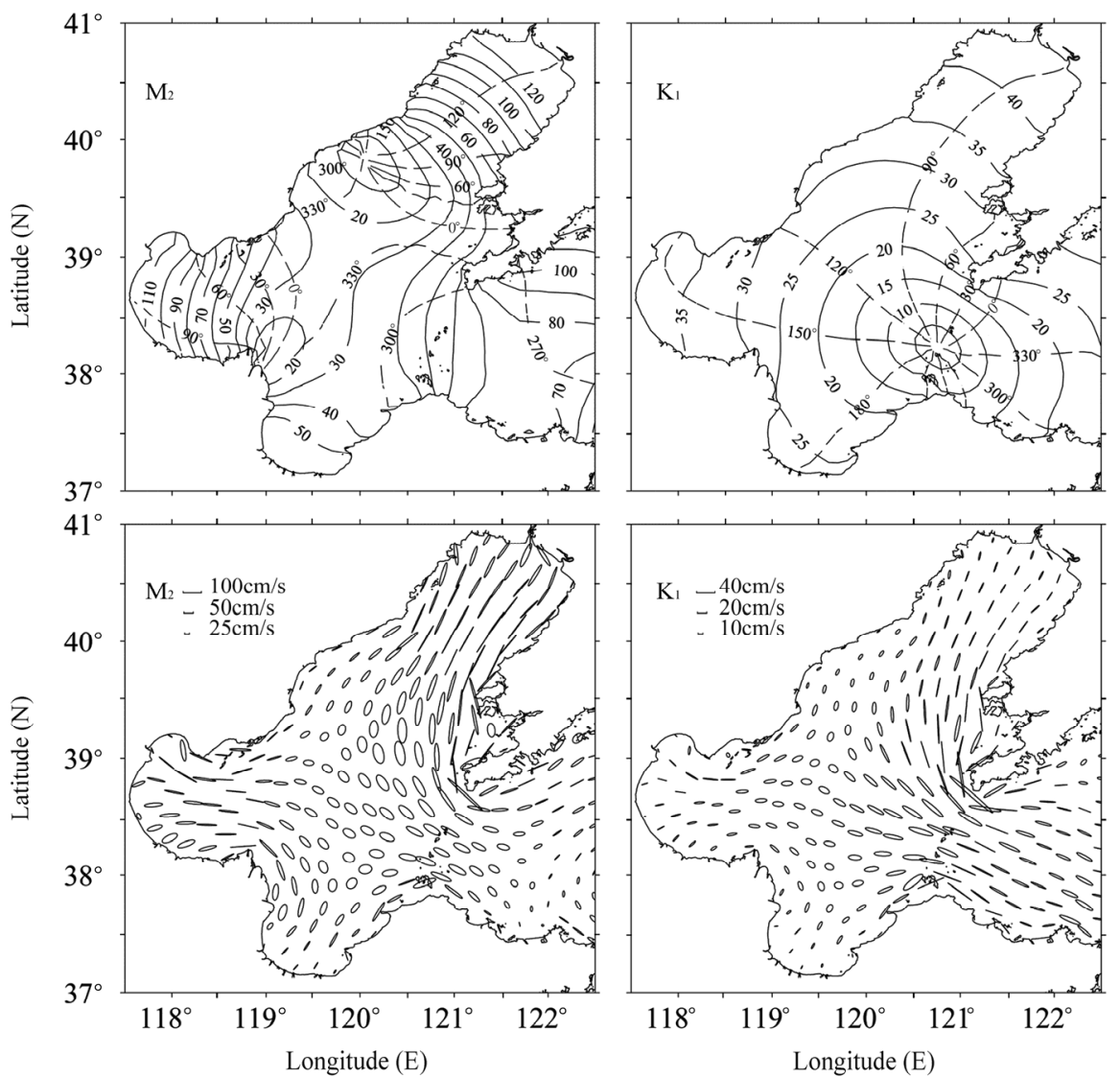

Figure 5. Co-amplitude line (solid, in $\mathrm{cm}$ ) and co-phase line (dashed, in degree) of $M_{2}$ and $K_{1}$ (upper panels) and their tidal current ellipses (lower panels).
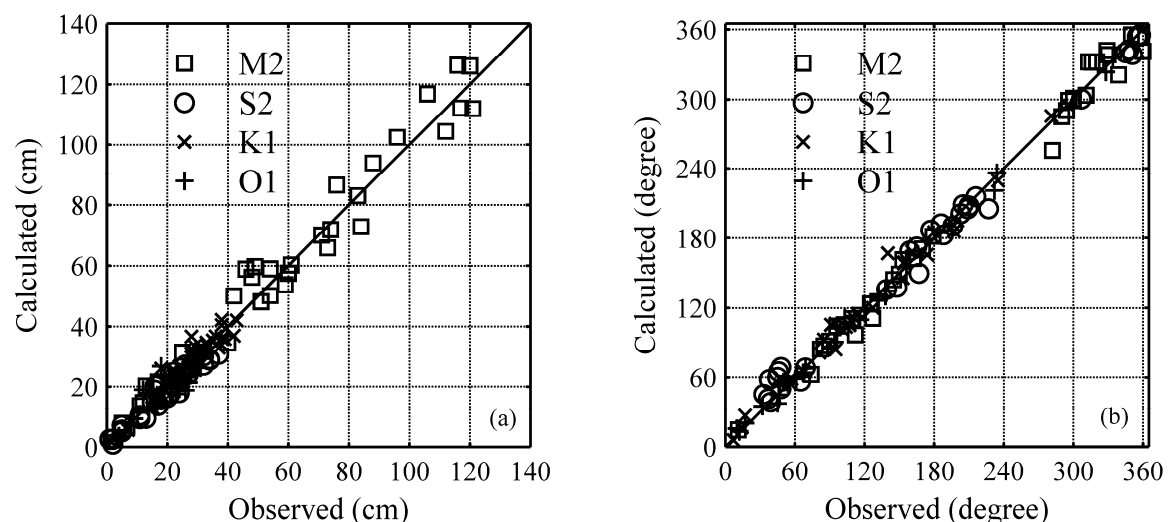

Figure 6. Comparison of harmonic constants derived from simulations (ordinate) and observations (abscissa) at 32 tidal stations as shown in Figure 3 for (a) amplitude and (b) phase. Different symbols denote different tidal constituents. 

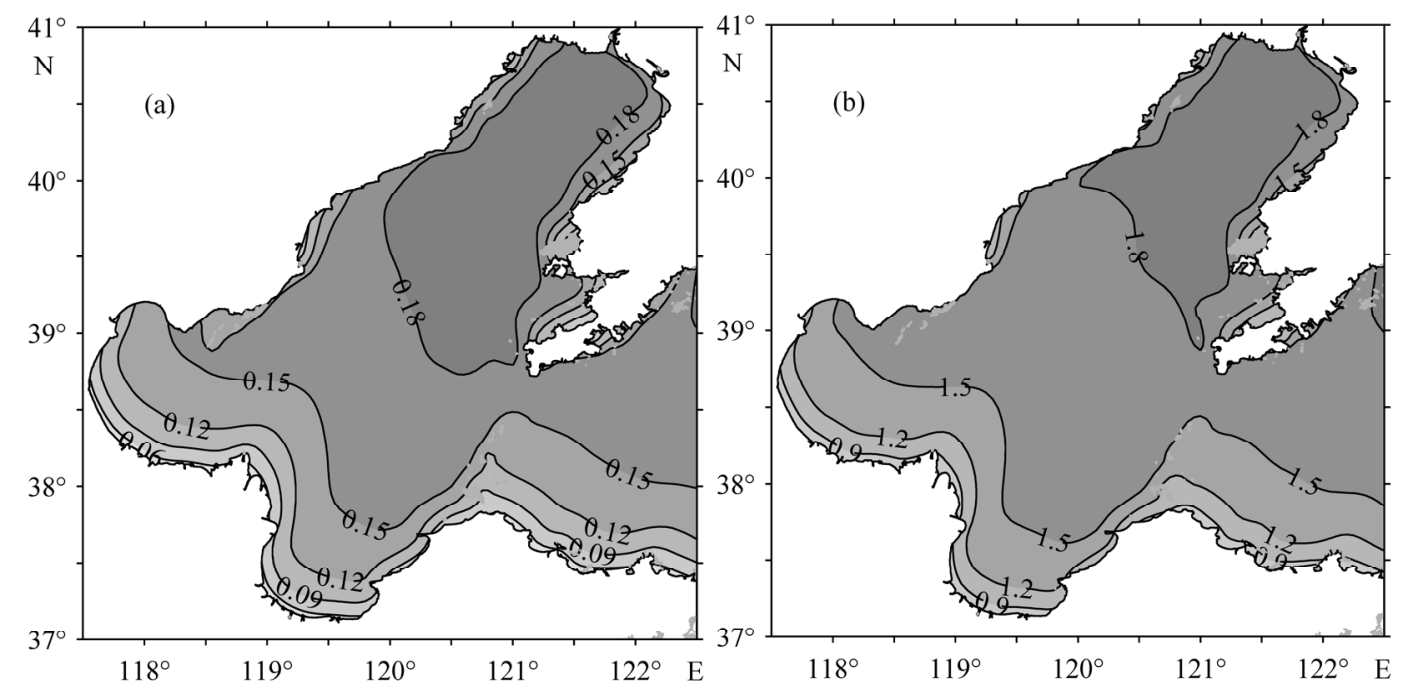

Figure 7. (a) Simulated significant wave height (unit: $\mathrm{m}$ ) and (b) averaged wave period (unit: s) at the beginning of the oil spill.

\begin{tabular}{|c|c|c|c|c|c|c|c|c|c|}
\hline & & \multicolumn{2}{|c|}{$H_{U}(\mathrm{~cm} / \mathrm{s})$} & \multicolumn{2}{|c|}{$G_{U}\left({ }^{\circ}\right)$} & \multicolumn{2}{|c|}{$H_{V}(\mathrm{~cm} / \mathrm{s})$} & \multicolumn{2}{|c|}{$G_{V}\left({ }^{\circ}\right)$} \\
\hline & & Observed & Calculated & Observed & Calculated & Observed & Calculated & Observed & Calculated \\
\hline \multirow{4}{*}{ Surface } & $M_{2}$ & 20.11 & 22.18 & 45.51 & 43.80 & 31.13 & 30.88 & 176.50 & 169.98 \\
\hline & $S_{2}$ & 4.79 & 4.94 & 122.34 & 131.98 & 7.38 & 7.39 & 236.41 & 250.65 \\
\hline & $K_{1}$ & 7.03 & 4.57 & 49.87 & 38.60 & 14.22 & 12.50 & 224.70 & 236.07 \\
\hline & $O_{1}$ & 6.32 & 4.15 & 13.94 & 358.41 & 8.73 & 7.48 & 189.43 & 171.97 \\
\hline \multirow{4}{*}{ Bottom } & $M_{2}$ & 16.85 & 15.06 & 15.46 & 35.72 & 25.88 & 22.78 & 156.52 & 165.66 \\
\hline & $S_{2}$ & 4.29 & 3.14 & 89.10 & 115.90 & 7.23 & 5.32 & 214.42 & 237.30 \\
\hline & $K_{1}$ & 3.22 & 3.39 & 52.74 & 66.15 & 16.52 & 10.24 & 238.84 & 231.27 \\
\hline & $O_{1}$ & 4.16 & 2.74 & 53.37 & 78.53 & 13.37 & 5.62 & 204.91 & 169.47 \\
\hline
\end{tabular}

A comparison between computed and current amplitudes and phases deduced from measurements (Qiao et al., 2008) at the current observation station can be seen in Table 2. The agreement in currents is good except for the, currents at the bottom. It should be noted that the measurement uncertainty is not considered. The wave parameters, including significant wave height and mean wave period at the beginning of the spill, are shown in Figure 7.

Figures 8 (a) and (b) are the observed distributions of the spilled oil slick on 12 and 15 June, respectively. Figures 9 (a) and (b) are the simulated distributions of the oil slick on 12 and 15 , respectively. Comparing Figures 9 (a) and (b) reveals an eastward movement of the simulated oil slick, which agrees with the main tendency of the spreading of the observed oil slick (see Figure 8). Also, the map of oil concentrations, computed from the density of particles per water volume unit, is presented in Figure 10. It can be seen that the center of the spill mass moves to $121.05^{\circ} \mathrm{E}, 38.45^{\circ} \mathrm{N}$ with the highest concentration about $1.4 \mathrm{mg} / \mathrm{L}$ until 12 June, moving along a northeasterly direction to $121.2^{\circ} \mathrm{E}$, $38.52^{\circ} \mathrm{N}$, with the highest concentration about $0.85 \mathrm{mg} / \mathrm{L}$ until $15 \mathrm{June}$.

The simulated vertical distributions of oil droplets are presented in Figure 11. Under the action of surface waves, particles have a preference for entraining in the water column. The turbulent mixing force may propel a few oil particles deeper into the water column. Owing to the effect of buoyancy, most particles will resurface. Unfortunately, there was no observed vertical distribution of an oil slick for comparison. Nevertheless, this result is reasonable according to the observed vertical distribution of air bubble (Thorpe, 1982). 

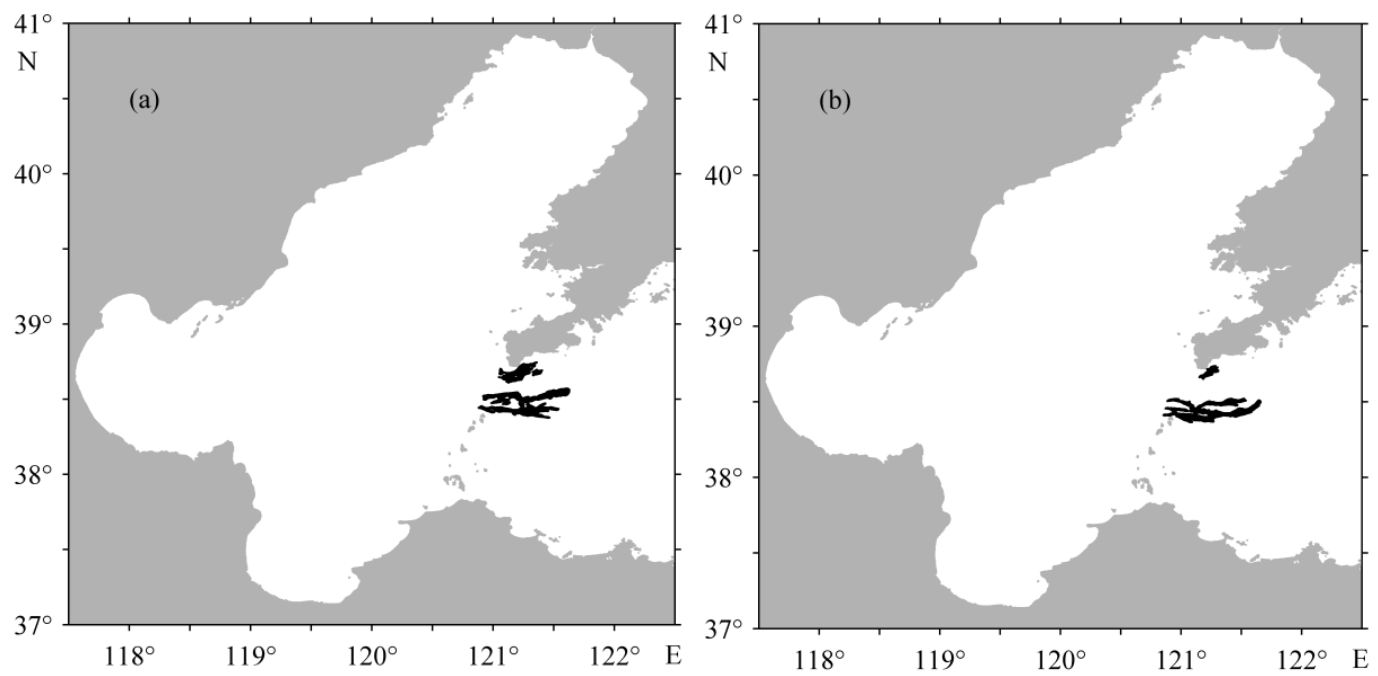

Figure 8. Snapshots showing the distributions of oil slick observed (a) on 12 June and (b) 15 June.
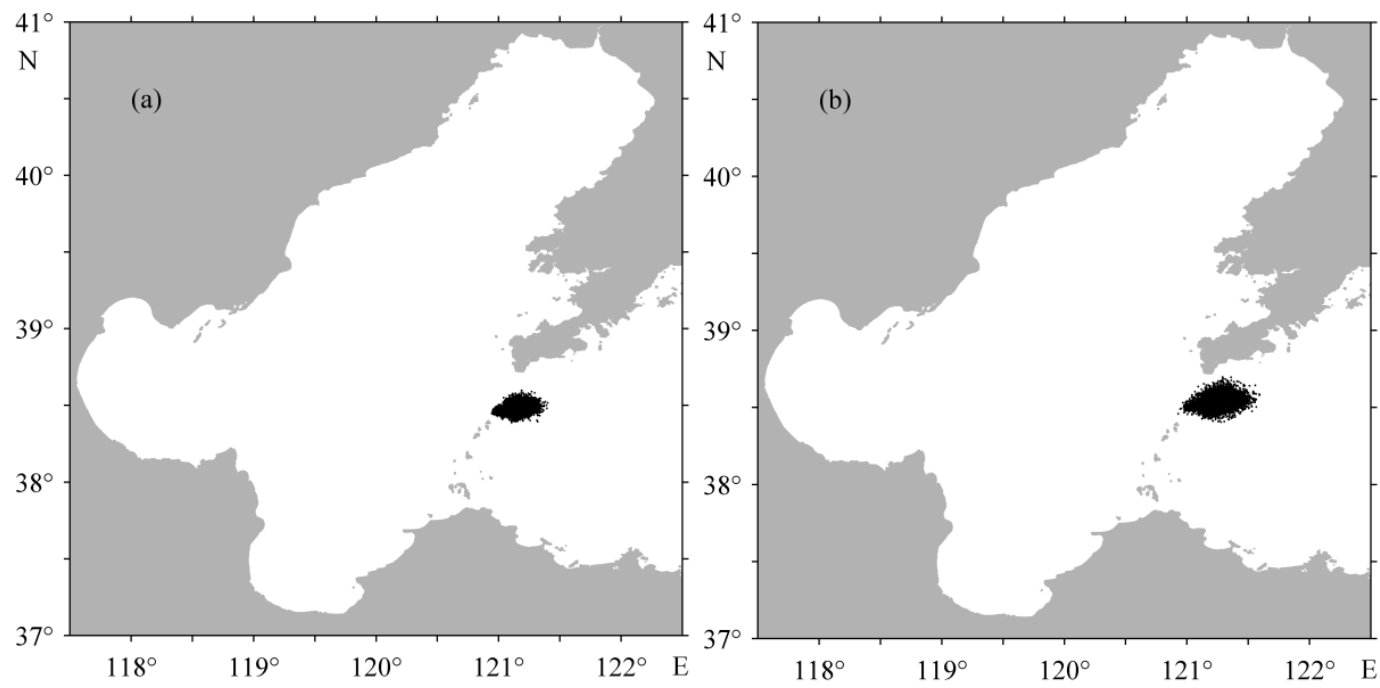

Figure 9. Snapshots showing the distributions of oil slick simulated (a) on 12 June and (b) 15 June.

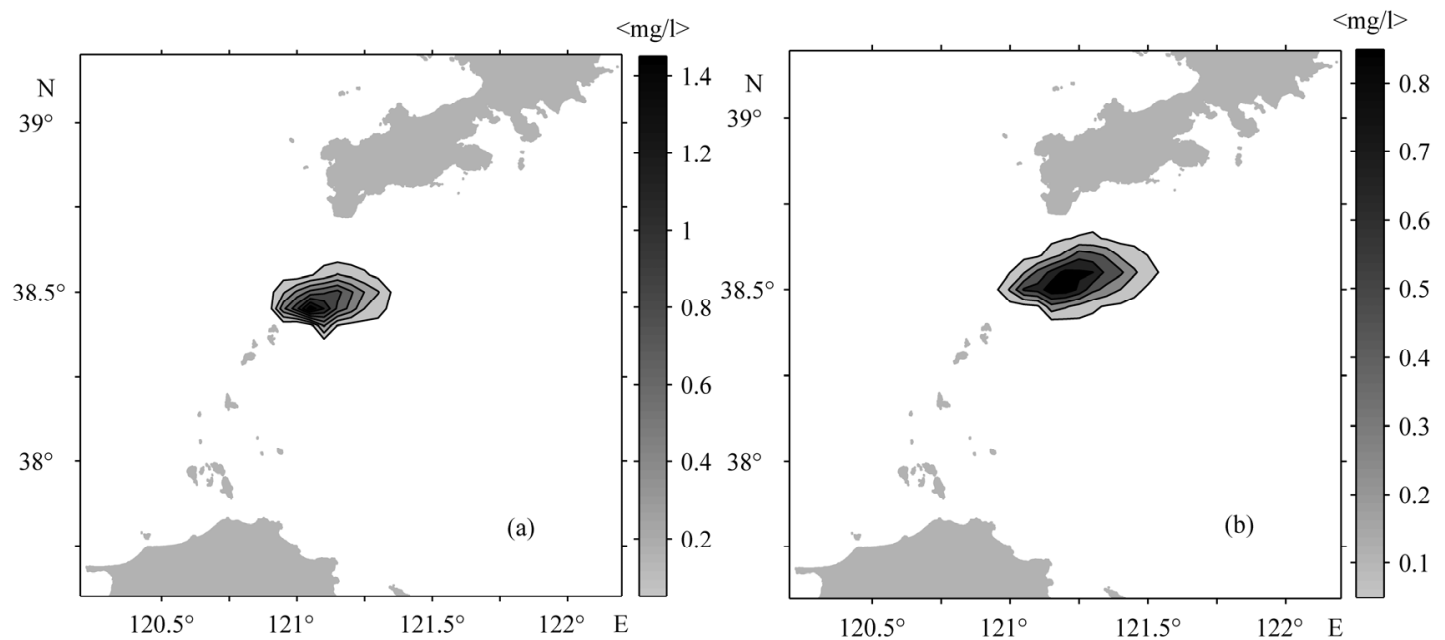

Figure 10. The computed oil concentrations (a) on 12 June and (b) 15 June. 

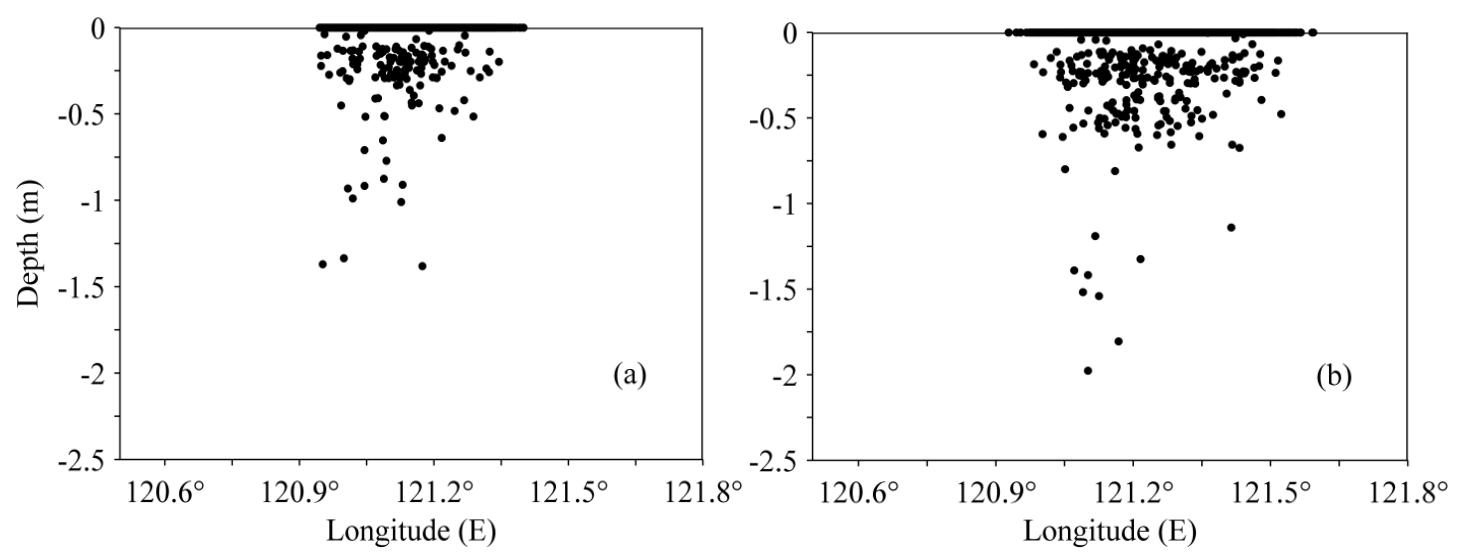

Figure 11. The vertical distributions of oil droplets simulated in the water column (a) on 12 June and (b) 15 June.

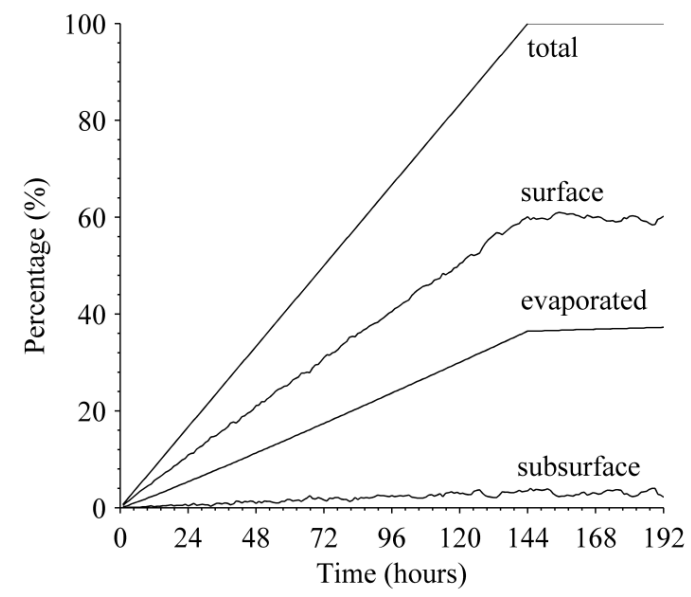

Figure 12. Time series of modeled oil components.

Figure 12 summarizes the computed oil fate as a time history of oil emitted, oil evaporated, and oil dispersed below the surface with an SSW wind of $3 \mathrm{~m} / \mathrm{s}$. As is seen, evaporation is the primary initial process involved in the removal of oil from the sea, i.e., more than $35 \%$. With a gentle breeze, only about $3.5 \%$ of the oil is dissolved and dispersed in the water column. There remains $60 \%$ of total oil on the surface until the end of the simulation.

Thus it seems that, generally speaking, even with rather poor information about wind conditions provided, the present model can at least give a first-order prediction of the oil-slick displacement. With improvement in the reliability of external information, such as wind conditions, better simulated results might be achieved.

\section{CONCLUSION}

The description of an integrated three-dimensional model for simulating oil-spill transport and fate in seas has been presented in this paper. The transport-fate module is based on the particle approach. The amount of oil released at sea is distributed among a large number of particles tracked individually. These particles move in a 3-D space. They are driven by water currents, wave- and wind-induced speed when they are on the water's surface, whereas they move vertically in the water column owing to buoyancy. Horizontal diffusion is simulated using a random walk technique, whereas vertical diffusion processes are solved on the basis of the Langeven equation. Three weathering processes, emulsification, dissolution and evaporation, which modify the characteristics of the surface oil, have been simulated.

An unstructured finite-volume parallel wave-ocean model is developed as the flow module to provide the hydrodynamic parameters to the transport-fate module. Using unstructured meshes provides great flexibility for modeling the flow in arbitrary and complex geometries, such as those of the Bohai Strait domain. Moreover, a surface-wave model is coupled with the ocean model. This coupling includes depth dependent wave-radiation-stress terms, Stokes' drift, and vertical transfer of 
wave-generated pressure to the mean momentum equation, wave dissipation as a source term in the turbulence kinetic energy equation and mean current advection and refraction of wave energy.

The integrated model has been applied to an oilspill accident that took place in the Bohai Strait (China). The flow module has been validated through the comparison of computed tidal elevations, phases and currents with measurements in the area. Results are in good agreement with observations. The simulated trajectories of the spilled oil slick were similar to the observed movement tendency of the slick, although rather poor wind data were provided. It should be noted that the simulated results could be improved if more accurate environmental data were provided. Further model validation by means of laboratory/field environmental data and integrate water quality model should be taken into account in the future. Generally speaking, the simulated results show that the model is useful for investigating the behavior of oil spills in an area of complex geography. This model can be used as a tool for estimating the impact of spilled oil on the marine environment, thereby providing useful information to assist spill response after a paroxysmal oil accident.

\section{ACKNOWLEDGMENTS}

This work was financially supported by the Nanjing Hydraulic Research Institute Foundation (Y212004).

\section{REFERENCES}

Chao, X.B., Shankar, N.J. and Cheong, H.F., 2001. Two- and three-dimensional oil spill model for coastal waters. Ocean Engineering, 28(12): 1557-1573.

Chao, X.B., Shankar, N.J. and Wang, S., 2003. Development and application of oil spill model for Singapore coastal waters. Journal of Hydraulic Engineering, 129(7): 495-503.

Chen, C.S. et al., 2007. A finite volume numerical approach for coastal ocean circulation studies: Comparisons with finite difference models. Journal of Geophysical Research, 112: C03018.

Editorial Board for Marine Atlas, 1992. Marine atlas of the Bohai Sea, Yellow Sea and East China sea: hydrology. China Ocean Press, Beijing, China, 524 pp.

Lonin, S.A., 1999. Lagrangian model for oil spill diffusion at sea. Spill Science and Technology Bulletin, 5(5): 331-336.

Periáñez, R., 2007. Chemical and oil spill rapid response modelling in the strait of Gibraltar-Alboran Sea. Ecological Modelling, 207(2-4): 210-222.

Periáñez, R. and Pascual-Granged, A., 2008. Modelling surface radioactive, chemical and oil spills in the strait of Gibraltar. Computers and Geosciences, 34(2): 163-180.

Qiao, L.L., Bao, X.W. and Wu, D.X., 2008. The observed currents in summer in the Bohai Sea. Chinese Journal of Oceanology and Limnology, 26(2): 130-136.

Shen, H.T. and Yapa, P.D., 1988. Oil slick transport in rivers. Journal of Hydraulic Engineering, 114(5): 529-543.

Shen, H.T., Yapa, P.D. and Petroski, M.E., 1986. Simulation of oil slick transport in great lakes connecting channels, Department of Civil and Environmental Engineering, Clarkson University, Potsdam, NY.

Thorpe, S.A., 1982. On the clouds of bubbles formed by breaking wind-waves in deep water, and their role in air - sea gas transfer. Philosophical Transactions of the Royal Society of London. Series A, Mathematical and Physical Sciences, 304(1483): 155-210.

Wang, J.H. and Shen, Y.M., 2010. Modeling oil spills transportation in seas based on unstructured grid, finite-volume, wave-ocean model. Ocean Modelling, 35(4): 332-344.

Wang, S.D., Shen, Y.M. and Zheng, Y.H., 2005. Two-dimensional numerical simulation for transport and fate of oil spills in seas. Ocean Engineering, 32(13): 1556-1571.

Wang, S.D., Shen, Y.M., Guo, Y.K. and Tang, J., 2008. Three-dimensional numerical simulation for transport of oil spills in seas. Ocean Engineering, 35(5-6): 503-510.

Yapa, P.D., Shen, H.T. and Angammana, K.S., 1994. Modeling oil-spills in a river Lake system. Journal of Marine Systems, 4(6): 453-471.

Zhang, B., Zhang, C.Z. and Ozer, J., 1991. Surf - a simulation model for the behavior of oil slicks at sea. In: J. Ozer (J. Ozer), Proceedings of the OPERA Workshop. Oil Pollution: Environmental Risk Assessment (OPERA), Dalian, China, pp. 61 - 85. 